\title{
Research Electricity Production Costs and External Compensation Mechanism
}

\author{
Dunnan Liu1, Xinming Liu1, Liaoyi Ning2, Haichao Wang', Yu Hu1, Yujie Xu1 \\ ${ }^{1}$ North China Electric Power University, Economics and Management, Beijing, China \\ ${ }^{2}$ Electric Power Research Institute of Economics and Technology, Liaoning Electric Power Company, \\ Shenyang, China \\ ${ }^{3}$ Dispatching Control Center, Anhui Electric Power Company, Hefei, China \\ Email: liudunnan@163.com, liuxinming 77@126.com, ningliaoyi@163.com, wanghaichao@ahepc.com.cn
}

Received December 2013

\begin{abstract}
China's power enterprises are mainly dominated by thermal power, thermal power is the key industry of coal consumption, so the thermal power enterprises have a fundamental influence on the environment, and how to not affect the vital interests of power enterprises under the condition of power plant to increase the strength of governance is to solve the current problem of letter. On the basis of various types of power generation enterprise environmental cost of thermal power, hydropower, wind power and nuclear power pollutant treatment cost were described, through the analysis of emission control scheme and the cost compensation of pollutants, environmental governance cost model, using a actual plant data, calculation of various pollutants compensation cost of thermal power plant, and according to the thermal power and wind power for quantitative comparison before and after compensation.
\end{abstract}

\section{Keywords}

The Cost of Environmental Governance; Compensation Mechanism; Low Carbon and Energy Saving; Pollutant Emission

\section{Introduction}

Power generation business is one of the energy-hungry countries' current relative emission situation that also highlights serious pollutants emission power industry has a different approach, seemingly clean energy generation in hydropower plants, wind farms and nuclear power plants there are also some easily ignored by the public contaminants, such as noise, oil, electromagnetic radiation, etc. [1-4]. So, for power generation companies, how can the sharing of environmental costs and compensation mechanisms for implementing pollution control is an important issue currently facing, can really cost effective implementation of environmental compensation mechanism will be to promote a low-carbon energy-saving power of economic development and achieve important strategic sustainable development in China's power industry.

Electricity production process would adversely affect the environment, as time goes by, environmental control costs will also increase [5]. Therefore, the total cost of electricity production should be the cost of production 
and environmental costs, and (as shown in Figure 1).

\section{Emissions from Power Plants Pollution Classification}

\subsection{Environmental Costs of Thermal Power Plant Pollution}

Our country is coal based power generation. Thermal power plants not only produce the electrical energy, but also produce a lot of soot, sulfur dioxide, carbon dioxide, nitrogen oxides, as well as wastewater and other pollutants. Therefore, thermal power plants take a certain amount of pollution reduction measures, and increasing the investment and operating costs; addition, the environmental protection department would like to plant a certain amount of sewage charges, which have formed a power plant environmental costs. Environmental costs of thermal power plants can be divided in Figure 2.

\subsubsection{The Desulfurization Ability of Pollution Source Environmental Cost}

Power industry is an important industry $\mathrm{SO}_{2}$ produced. Perform the installation of desulfurization equipment for

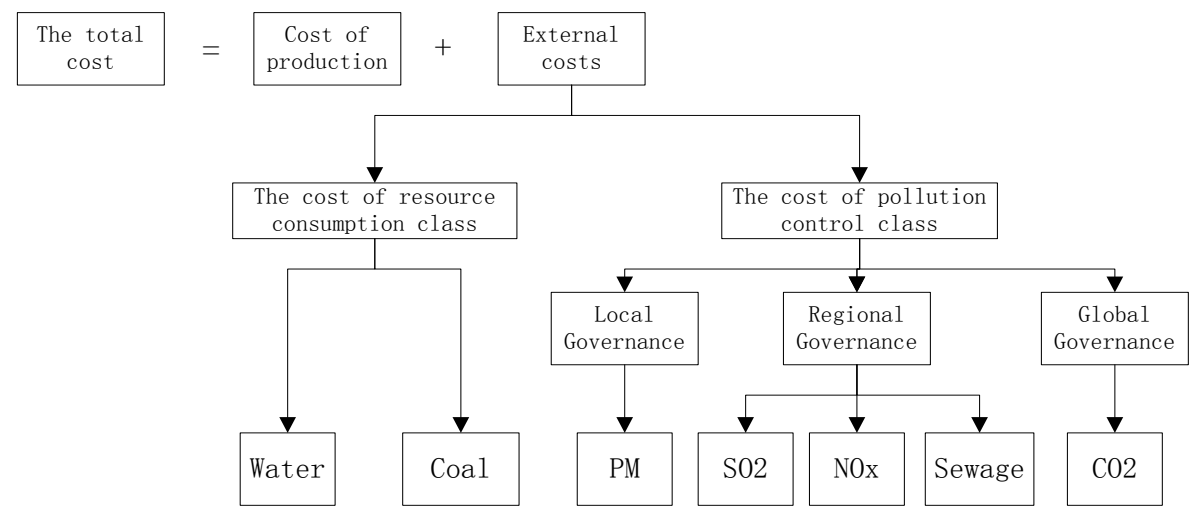

Figure 1. The total cost of power production.

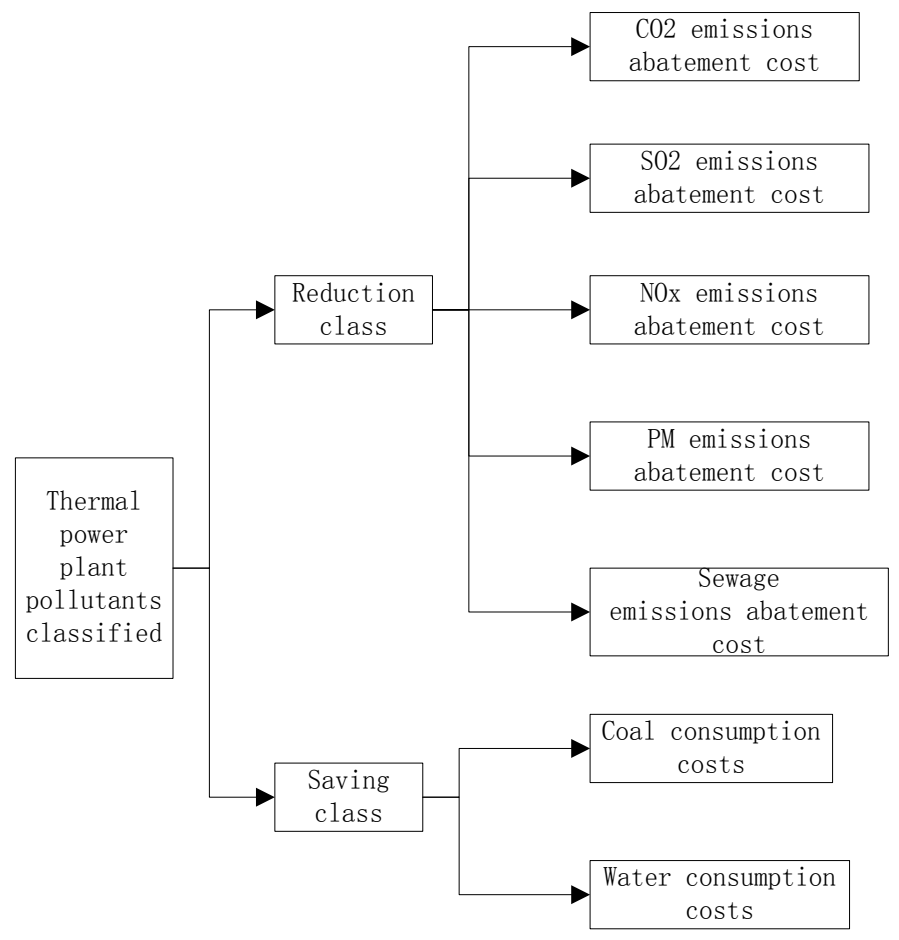

Figure 2. Classification of power plant pollutants. 
$\mathrm{SO}_{2}$ emissions can be reduced by more than $60 \%$ of sulfur dioxide emissions. Under normal circumstances, the investment per kilowatt of installed capacity of thermal power with coal desulphurization facilities needed about 600 - 1500 RMB, shown in Figure 3.

\subsubsection{The Denitrification Capacity of the Environmental Costs of Pollution Sources}

Treatment of nitrogen oxides commonly used mainly for thermal power unit installed denitration device, as shown in Figure 4. On the basis of flue gas $\mathrm{DeNO}_{\mathrm{x}}$ Technology is new, can make the nitrogen oxide emissions reduction of about $70 \%$. The integrated information, the future of denitration price subsidies will be increased to 1 points/degree.

\subsubsection{The Dust Removal Ability of Pollution Source Environmental Cost}

Installation of bag type dust collector efficiency is high, which can make the inhalable particulate matter $<30$ $\mathrm{mg} / \mathrm{nm}^{3}$, as shown in Figure 5. Through the dust removal technology of coal-fired boiler flue gas dust removal performance of the actual, the highest removal efficiency reached $94.01 \%$.

\subsubsection{The Sewage Treatment Capacity of the Environmental Costs of Pollution}

In the thermal power plant, the main wastewater with circulating water treatment chemical sewage, waste water,

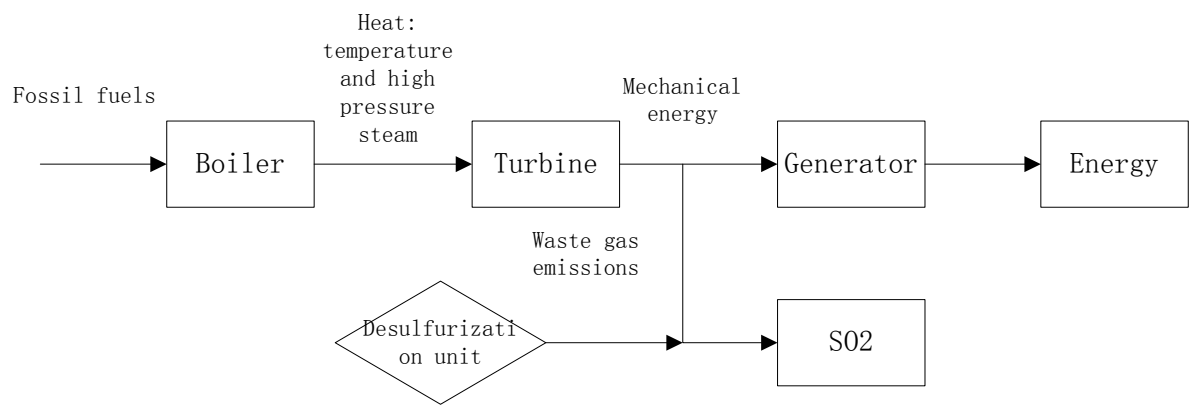

Figure 3. Sulfur dioxide emission principle.

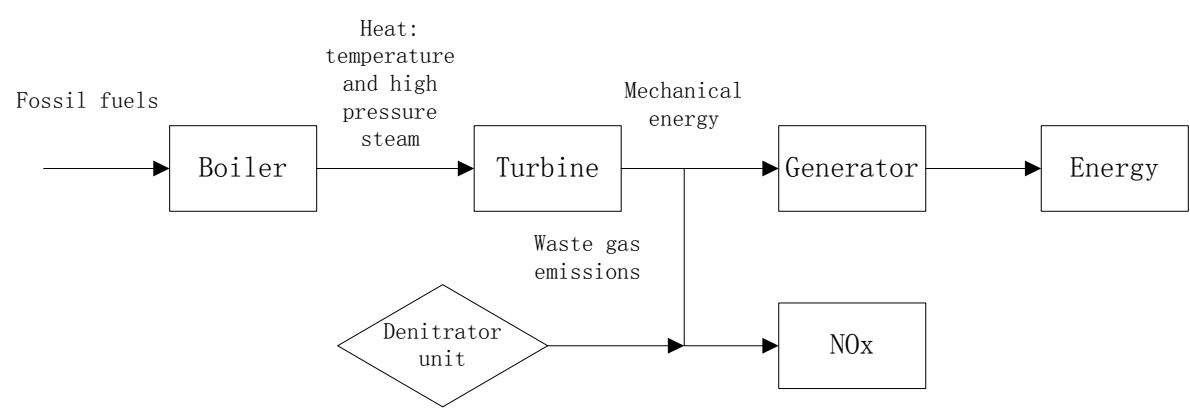

Figure 4. Nitrogen oxides emission principle.

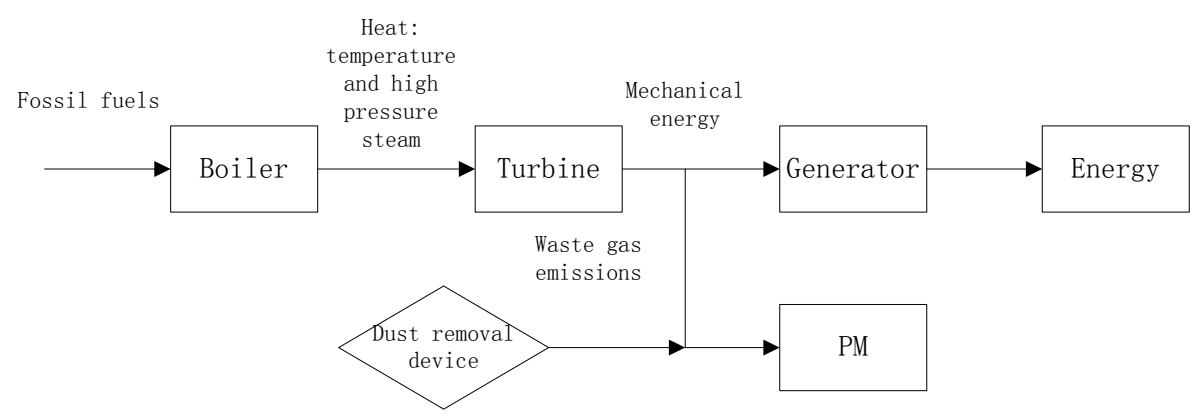

Figure 5. The respirable particulate matter emission principle. 
dust removal and desulfurization system drainage, wastewater, life wastewater plant coal handling system, the circulating water sewage accounted for $70 \%$ of the total waste water of power station, waste water greatly increases the cost of power generation, according to the standard whether emission concentration if exceed the standard, wastewater discharge fees by $0.05 \mathrm{RMB} /$ ton levy.

\subsection{The Other Types of Power Plant Pollution Environmental Costs}

Compared with thermal power plant emission of pollutant, hydropower, wind power and nuclear power is clean energy, but in hydropower, wind power and nuclear power of pollutants in the process of power generation will still be inevitable, although these emissions is small, still need to control and prevent the pollution prevention, improve and extend the scope of pollution intensity.

\section{Sources for Power Plants of Such Governance Cost Compensation}

According to the different external costs, pollution can be divided into local and global pollution, regional pollution, through the various treatment methods to compensate for the pollution of the environment, such as taxation, emissions trading, and so on.

\subsection{Compensation Based on Global Pollution}

Global pollution is mainly established by the greenhouse effect of $\mathrm{CO}_{2}$.

\subsubsection{Calculation of Average Carbon Dioxide Emission Factors}

Average carbon dioxide emission factor refers to unit power plant coal consumption in thermal power plants and the amount of emissions of carbon dioxide.

Total emissions of carbon dioxide is multiplied by the unit's fuel consumption, net calorific value of fuel and carbon dioxide emission factors, then divided by the total grid electricity (that is, electricity consumption unit minus the integrated plant), the average carbon dioxide emission factors is available, the calculation formula is as follows:

$$
f_{\mathrm{CO}_{2}}=\frac{M_{\mathrm{CO}_{2}}}{Q}=\frac{F C_{i} \times N V C_{i} \times M_{\mathrm{CO}_{2}, i}}{Q}
$$

In the formula, $M_{\mathrm{CO}_{2}}$ : total emissions of carbon dioxide(t); $Q$ : total on-grid power units(MWh); $F C_{i}$ : the fuel consumption of a unit $i$ (unit of mass or volume); $N V C_{i}$ net calorific value of fuel $i$ (Energy content, $\mathrm{GJ} / \mathrm{unit}$ of mass or volume); $h_{\mathrm{CO}_{2}, i}$ : carbon dioxide emission factors of fuel $i\left(\mathrm{tCO}_{2} / \mathrm{GJ}\right) ; i$ : the consumption of types of fossil fuels by the unit.

\subsubsection{The International Carbon Emissions Trading}

International nature of carbon emission rights is limited to the environmental capacity of carbon use. Generally use the total and trading in benchmark:

1) The total amount of transactions (or CAP-and-trade): break down carbon dioxide emissions credits to emissions, then make the allocation to the power plants, and allow it to trade.

2) Baseline and credit emissions' trading is based on project-based carbon emissions control mode. Combined with realistic conditions of a baseline (usually under unit energy consumption or emission or emission intensity per unit of output), credit will be given actual emissions below a baseline, may freely trade its credits.

\subsection{Compensation Based on Regional Pollution}

Regional pollutant primarily established by the pollutant emissions of $\mathrm{SO}_{2}, \mathrm{NO}_{\mathrm{x}}, \mathrm{PM}$ and waste water.

1) Calculation of average emission factors for sewage lows:

Coal-fired power plant in the production process emits large amounts of wastewater. The formula is as fol-

$$
f_{\mathrm{s}}=M_{\mathrm{s}} / Q
$$

In the formula, $M_{\mathrm{s}}$ : the total amount of sewage (t); $Q$ : total on-grid power units (MWh). 
2) Calculation of average emission factors for sulfur dioxide

Sulfur contained in coal by combustion oxidation of $\mathrm{SO}_{2}$ emissions into the atmosphere can cause pollution to the environment, can be calculated by monitoring the emissions of sulfur dioxide, and sulfur dioxide emissions, the greater, the more detrimental to the environment. The formula is as follows:

$$
f_{\mathrm{SO}_{2}}=M_{\mathrm{SO}_{2}} / \mathrm{Q}
$$

In the formula, $M_{\mathrm{SO}_{2}}$ : total emissions pollutants of $\mathrm{SO}_{2}(\mathrm{t}) ; \quad Q$ : total on-grid power units (MWh).

3) Calculation of average emission factors for $\mathrm{NO}_{\mathrm{x}}$

Calculated by monitoring the emissions of nitrogen oxides, total emissions of nitrogen oxides, the greater, the more detrimental to the environment. The formula is as follows:

$$
f_{\mathrm{NO}_{X}}=M_{\mathrm{NO}_{X}} / \mathrm{Q}
$$

In the formula, $M_{\mathrm{NO}_{X}}$ : total emissions of nitrogen oxides (t); $Q$ : total on-grid power units (MWh).

4) Calculation of average emission factors for $P M$

Calculated by monitoring the emissions of PM and PM emissions, the greater, the more detrimental to the environment. The formula is as follows:

$$
f_{P M}=M_{P M} / Q
$$

In the formula, $M_{P M}$ : total emissions of PM (t); : total on-grid power units (MWh).

\subsection{Compensation Based on Local Pollution}

Local pollutants for coal in power plants and water resource depletion of natural resources, such as the costs of environmental governance in place.

1) The measurement of Water consumption factor

Water consumption rates reflect the depletion of water resources in the production process of coal-fired power plants, coal-fired power plants needed to produce $1 \mathrm{kWh}$ or supply electrical energy consumption of water resources.

The actual calculation formula of water consumption is:

$$
f_{\mathrm{w}}=M_{\mathrm{w}} / Q
$$

In the formula, $M_{\mathrm{w}}$ : total consumption of water (t); $Q$ : total on-grid power units (MWh). These data can be obtained through plant research and statistics on the actual, or depending on the installed capacity of unit average analogy estimated.

2) The measurement of coal consumption rate factor indicator

Coal-fired power plant consumes the coal resources in the production process. Associated with the thermal efficiency of the power plant coal consumption rate, the higher the thermal efficiency, the lower the power supply coal consumption rate.

The actual calculation formula of coal consumption rate is:

$$
f_{c}=M_{c} / Q
$$

In the formula, $M_{c}$ : total consumption of coal (t); $Q$ : total on-grid power units (MWh). These data can be obtained through plant research and statistics on the actual, or depending on the installed capacity of unit average analogy estimated.

\section{Power Plants Cost Compensation Mechanism for Environmental Governance}

Power plants cost compensation mechanism is based on environmental governance, "Who is who compensation, the establishment of a complete economic leverage" as the core, that is through the power companies to develop their own emissions compensation standards, regional and global pollution through sharing and transactions carried out in the form of processing, while taxes need to be imposed through these economic instruments can play a macro-control, support and development of clean energy goals.

\subsection{Compensation Mechanism for Resource Consumption Class}

Resource Tax Implementation of “universal levy, differential regulation” imposed principle. The "universal levy” 
has two meanings, one resource for all taxable goods within the resource tax should be levied, and second of all taxable goods resource exploitation or producer must pay resource tax; meaning "differential regulation" is refers to the differential income by different resource endowments, mining conditions, geographical location and other objective conditions generated by the implementation of differential tax to be adjusted.

China's coal and water resources are limited. After the implementation of tax system, based on the resource tax "levied generally, differential regulation" principle, through the rational design of tariff rates, fair tax, coal and water resources exploitation units inevitable strengthening management, scientific and rational development and utilization of coal resources and water resources, improve operational efficiency and effective supply. By adjusting the price lever, power generation enterprises to improve the utilization of coal and water resources, reduce waste and losses, improve their overall effectiveness.

\subsection{Compensation Mechanism for Pollutant Reduction Class}

\subsubsection{Global Pollutant Compensation Mechanism}

Carbon tax is recognized as the international community is one of the effective economic measures to reduce carbon dioxide emissions, but also emissions reflect policy. Carbon dioxide emission reduction policies can be divided into two levels, the international level, the second is the domestic level. International level to determine the concentration of carbon dioxide is mainly to control the world's largest carbon emissions below a certain risk level allowed, and follow certain rules between countries and regions in carbon emission rights allocation, clear or partly clear national and regional carbon limit emissions. Domestic level is generally through a carbon tax, carbon dioxide emissions reduction policy goals.

Most recently levied a carbon tax are mixed, rate design consists of two parts, one part is determined by the energy of the carbon content of all solid and liquid fossil fuels including coal, petroleum and its various products have their pay that portion of the carbon content of a carbon tax; another part is determined by the amount of heat energy, mainly refers to non-fossil energy and fossil energy, such as electricity tax.

\subsubsection{Regional Pollutants Compensation Mechanism}

Emissions of pollutants cost compensation mechanism is to be embodied emissions trading, emissions trading within the power generation companies in environmental supervision and management department allocated the amount, and ensure that the rights will be exercised without prejudice to any other rights and interests of the public environment premise, according to the rights of pollutants discharged into the environment. When power generation companies select the right not to be executed when a certain price it can be transferred to other power generation companies.

\subsubsection{Local Pollutants Compensation Mechanism}

Local pollutants compensation mechanism mainly refers to the method of the power generation process remain within the local pollutant emissions compensation, usually the easiest is to compensate for the actual treatment costs, follow the "polluter pays compensation" principle, based on the type of pollutant emissions and impose governance contained in proportion to the cost of production for each department, and finally, to increase the power production process emissions link suggestions for improvement.

\section{Analysis of the External Costs of Electricity Production Instance}

\subsection{Compensation for Each Pollutant Condition of Thermal Power Plant}

For coal resource consumption, the present stage of its resource tax, resource tax, whether or paid by the power companies paid by the coal companies, will lead to rising coal prices, the share of coal in the provinces of A is about $560 \mathrm{RMB} /$ ton, while generation standard coal consumption of approximately 400 g/degrees, so the cost of coal consumption is about $0.224 \mathrm{RMB} / \mathrm{kWh}$, coal resource tax levied by local 5\%, there Table 1.

State A thermal power plant of industrial water price is about 2.86 RMB/ton, with a $600 \mathrm{MW}$ power plant, for example, wastewater emissions $3533 \mathrm{t} / \mathrm{h}$, so the power consumption of water $5.9 \mathrm{~kg} / \mathrm{degree}$, there Table 2 .

Compensation cost of thermal power plants of various pollutants situation can be divided into three cases: It has been found has been compensated; been found uncompensated; did not find uncompensated. Has been found to have compensation means the current benchmark price already includes compensation cost control pollutants, 
Table 1. Effect of A province coal resource tax on coal consumption.

\begin{tabular}{cc}
\hline Share coal (RMB/ton) & 560 \\
Coal consumption (g/degree) & 400 \\
Coal resource tax (RMB/ton) & 28 \\
Coal consumption costs (RMB/kWh) & 0.224 \\
Coal resource tax cost (RMB/kWh) & 0.0112 \\
The proportion of coal resource tax & $5 \%$ \\
\hline
\end{tabular}

Table 2. Effect of A province's power plant sewage treatment in water consumption in power generation.

\begin{tabular}{cc}
\hline Industrial water price (RMB/ton) & 2.86 \\
Electricity and water consumption (kg/degree) & 5.9 \\
Sewage treatment (RMB/ton) & 0.05 \\
Electricity and water consumption costs (RMB/kWh) & 0.017 \\
Sewage treatment costs (RMB/kWh) & 0.0003 \\
The proportion of sewage treatment & $1.7 \%$ \\
\hline
\end{tabular}

or contaminants develop levied on the phenomenon. No compensation has been found to have been found is the more serious pollutants, but due to technical limitations, such as the objective conditions of the phenomenon of governance cannot be compensated. Refers not found uncompensated harm caused by pollutants smaller, usually unnoticed, so I cannot get effective governance and compensation.

\subsection{Based on Thermal Power and Wind Power Compensation Costs under the Social Costs of the Mechanism}

Today, thermal power tariff is low, most users will choose to buy thermal power, but after taking into account the external costs of electricity production, will need to calculate the cost of environmental pollution to compensate tariff, in which case, we can see that adding thermal power tariff the total cost will be greater than the external indicators of various pollutants in clean energy tariff, so that users choose the types of power generation will have a choice, Table 3 is a province of the benchmark price.

Thermal power tariff join desulfurization out of stock after $0.448 \mathrm{RMB} / \mathrm{kWh}$, while wind power through national subsidies reached $0.61 \mathrm{RMB} / \mathrm{kWh}$, this comparison is to buy thermal power comparison economy, but based on the premise of social cost, thermal power cannot just simply consider themselves tariff, also need to add on the cost of compensation for environmental damage control

$$
C_{T}+\sum C_{E X}>C_{W}
$$

Where $C_{T}$ is the benchmark price of thermal power, the external costs of electricity generated by $C_{E X}$, which includes all of the thermal power plant pollution control compensation costs, $C_{W}$ benchmark price of wind power. According to $\mathrm{CO}_{2}$ emissions and $\mathrm{PM}$ emission factors and provinces A cost equivalent of, PM emission factors available in the future treatment costs can be achieved $\mathrm{CO}_{2}$ is $0.084 \mathrm{RMB} / \mathrm{kWh}$, the cost of governance $\mathrm{PM}$ is $0.092 \mathrm{RMB} / \mathrm{kWh}$. So it can be shown in Table 4.

\subsection{Based on Comprehensive Environmental External Costs of Electricity into Production Estimates}

The $f_{r}$ and on behalf of contaminants through the consumption of resources in Chapter 3 of the average emission rate factor $f_{p}$ corresponding multiplying $e_{r}$ and on behalf of representatives of the cost of resource consumption and pollution control class equivalent of the cost of equivalent class $e_{p}$, you can get a unit of electricity should be 
paid integrated environmental costs (in RMB/kWh), namely:

$$
\begin{aligned}
C_{t} & =C_{r}+C_{p} \\
& =f_{r} \times e_{r}+f_{p} \times e_{p} \\
& =f_{w} \times e_{w}+f_{c} \times e_{c}+f_{\mathrm{s}} \times e_{s}+f_{\mathrm{CO}_{2}} \times e_{\mathrm{CO}_{2}}+f_{\mathrm{SO}_{2}} \times e_{\mathrm{SO}_{2}}+f_{\mathrm{NO}_{2}} \times e_{\mathrm{NO}_{2}}+f_{P M} \times e_{P M}
\end{aligned}
$$

where $C_{r}, C_{p}$, respectively class resource consumption and pollution control costs per unit of electricity class.

Integrated environmental costs through the above calculation, corresponding to different ways of generating a unit of electricity to be paid (in RMB/kWh) as shown in Tables 4 and 5. From the table: the use of $1000 \mathrm{MW}$ coal-fired units for power, integrated environmental costs need to be paid in addition to the price of 0.29 $\mathrm{RMB} / \mathrm{kWh}$; utilize $600 \mathrm{MW}$ coal-fired units for power, need to pay the cost of $0.38 \mathrm{RMB}$ integrated environmental/kWh; utilization of $300 \mathrm{MW}$ coal-fired units for power, need to pay the cost of $0.57 \mathrm{RMB}$ integrated environmental/kWh; rather use $9 \mathrm{E}$ gas turbine unit types, integrated environmental costs need to pay 0.13 $\mathrm{RMB} / \mathrm{kWh}$; utilize 9F types of gas turbine units, integrated environmental costs need to pay $0.11 \mathrm{RMB} / \mathrm{kWh}$.

Table 3. Province of A benchmark price reference value of various kinds of power generation.

\begin{tabular}{cc}
\hline Unit Type & Benchmark price (RMB/kWh) \\
\hline Thermal power plants & 0.448 \\
hydropower plants & 0.337 \\
nuclear power plants & 0.43 \\
wind farms & 0.610 \\
\hline
\end{tabular}

Table 4. Province of A benchmark price reference value of various kinds of power generation.

\begin{tabular}{ccc}
\hline & $\begin{array}{c}\text { Thermal power } \\
(\mathrm{RMB} / \mathrm{kWh})\end{array}$ & $\begin{array}{c}\text { Wind Power } \\
(\mathrm{RMB} / \mathrm{kWh})\end{array}$ \\
\hline $\begin{array}{c}\text { Compensation mechanism does } \\
\text { not consider the social costs } \\
\text { Consider the social cost } \\
\text { compensation mechanism }\end{array}$ & 0.448 & 0.610 \\
\hline
\end{tabular}

\begin{tabular}{|c|c|c|c|c|c|}
\hline \multirow{2}{*}{$\begin{array}{c}\text { Unit } \\
\text { Type }\end{array}$} & \multicolumn{3}{|c|}{ Coal-fired units } & \multicolumn{2}{|c|}{ Gas-fired units } \\
\hline & $\begin{array}{l}1000 \\
\text { MW }\end{array}$ & $600 \mathrm{MW}$ & $300 \mathrm{MW}$ & $9 \mathrm{E}$ & $9 \mathrm{~F}$ \\
\hline Water & 265.3 & 350.7 & 551.3 & 116.6 & 99.0 \\
\hline Coal & 0.82 & 0.85 & 0.92 & 0.76 & 0.72 \\
\hline Sewage & 0.001 & 0.009 & 0.033 & 0 & 0 \\
\hline $\mathrm{CO}_{2}$ & 20.2 & 25.5 & 19.9 & 13.5 & 12.9 \\
\hline $\mathrm{SO}_{2}$ & 0.18 & 0.37 & 0.19 & 0.002 & 0.002 \\
\hline $\mathrm{NO}_{\mathrm{x}}$ & 0.24 & 0.57 & 1.15 & 0.87 & 0.81 \\
\hline $\mathrm{PM}$ & 0.92 & 0.96 & 1.04 & 0.86 & 0.81 \\
\hline Cs & 287.7 & 379.0 & 573.6 & 132.6 & 114.3 \\
\hline
\end{tabular}

Table 5. Of the different types of generators comprehensive environmental cost estimation results (RMB/MWh). 


\section{Conclusion}

To analyze the status of various types of thermal power generation companies environmental costs, classify, elaborate the current level of various pollution control methods, and based on environmental compensation mechanism, to analyze the carbon emissions and pollutant emissions trading compensation mechanism, and finally study the environmental cost of the comprehensive management model, draw on the actual province of pollutant emissions data, estimate its thermal power plants of various pollutants compensation cost position and thermal power and wind power for quantitative comparison of before and after the implementation of the compensation mechanism

\section{References}

[1] Fang, T., Li, C.-H. and Zhang, L.-Z. (2005) Research on the Environmental Cost of Power Generation Enterprises. Electric Power, 38, 16-20.

[2] Yu, J., Li, Y. and Xia, A.-B. (2009) The Optimization Strategy of Generation Scheduling in Distributed Environment Protection and Economic Benefit. Proceedings of the CSEE, 29, 63-68.

[3] Liu, J.-J., Jiang, S.-H. and Gu, Y.-J. (2005) Analysis and Calculation of the Environmental Cost of Coal Fired Power Plant. Electric Power Technologic Economics, 17, 60-62.

[4] Kang, C.-Q., Chen, Q.-X. and Xia, Q. (2009) Prospects of Low Carbon Power Technology. Power System Technology, 33, 1-7.

[5] Liu, D.-H., Yang, Y.-P., Yang, K., Li, D.-Q. and Yang, Z.-P. (2005) Study on Power Supply Cost of Power Plant Considering Environment Cost. Electric Power, 38, 24-28. 